\title{
Diversidade e sentidos do patrimônio cultural: uma proposta de leitura da trajetória de reconhecimento da cultura afro-brasileira como patrimônio nacional
}

Antonio Gilberto Ramos Nogueira*

Resumo. Considerando que o reconhecimento e a valorização da diversidade cultural pressupõem uma reeducação das relações étnico-raciais para além dos muros escolares, o texto busca articular as diretrizes que norteiam o processo de reelaboração da nova perspectiva de ensino para se pensar a questão da brasilidade à ressemantização do conceito de patrimônio cultural. Tomando como base os decretos e leis da política oficial de preservação do patrimônio cultural no Brasil do final do século $\mathrm{XX}$, o texto reflete a trajetória de construção do patrimônio como um longo processo de luta para a valorização e reconhecimento da cultura afro-brasileira.

Palavras-chave: Patrimônio Cultural. Diversidade. Educação Patrimonial. Identidade. Memória.

* Professor do Departamento de História da UFC. Doutor em História Social - PUC/SP. O texto é resultado das reflexões e demandas do Grupo de Estudos e Pesquisa em Patrimônio e Memória-UFC, sob minha coordenação. Email: antonioantonio@uol.com.br

Anos 90, Porto Alegre, v. 15, n. 27, p.233-255, jul. 2008 
Diversidade e sentidos do patrimônio cultural: uma proposta...

Desde a edição da Lei n. 10.639 de 2003, que introduziu a obrigatoriedade do estudo da história e cultura afro-brasileira e africana no currículo escolar da educação básica, foi lançado um grande desafio: corrigir a orientação eurocêntrica que marcou a constituição do sistema pedagógico brasileiro. Não se trata de uma simples mudança de foco, adverte o documento, mas de uma opção política de conotação pedagógica.

É preciso desenvolver políticas de ações afirmativas e de reparos, tendo em vista as diferentes contribuições histórico-culturais dos povos indígenas, dos descendentes de asiáticos, africanos e europeus. A ampliação do foco dos currículos escolares para a diversidade, em sentido lato, objetiva a construção de uma educação plural em consonância com uma sociedade multicultural e pluriétnica. Uma reeducação das relações étnico-raciais é o que propõe o documento Diretrizes Curriculares Nacionais para a Educação das Relações Étnico-Raciais e para o Ensino de História e Cultura Afro-Brasileira e Africana. Pluralidade e diversidade cultural estão no centro do debate.

O sucesso das políticas públicas de Estado voltadas para o reconhecimento e a valorização da identidade, da cultura e da história dos negros brasileiros depende de uma série de condicionantes que vão desde as condições ideais para o ensino e aprendizagem de todos os brasileiros nos diferentes níveis de ensino, como também um conjunto de estratégias e ações articuladas no âmbito das políticas públicas educacionais e patrimoniais e movimentos sociais. Ou seja, o reconhecimento e a valorização da diversidade cultural pressupõem uma reeducação das relações étnico-raciais conformadora com uma forma do pensar e agir para além dos muros escolares.

Nesta perspectiva, a educação patrimonial com vistas a um aprendizado a partir do patrimônio cultural afro-brasileiro é convocada como estratégia importante na consolidação desse projeto. É um movimento que busca igualmente uma reeducação para o patrimônio histórico e cultural brasileiro: "Defender o nosso patrimônio histórico 
e artístico é alfabetização", já dizia Mário de Andrade, no momento fundador e formulador de uma política de preservação do patrimônio cultural brasileiro na década de 1930.

Perseguindo essas considerações, o presente texto convida o leitor a acompanhar um roteiro de discussão sobre a idéia de patrimônio cultural e sobre as políticas de preservação a ele relacionadas. O sentido amplo e plural de patrimônio - expressão da diversidade cultural consubstanciada em manifestações tangíveis ou intangíveis, consagradas ou não consagradas - tem se revelado importante fonte de conhecimento sobre a relação passado/presente e - por que não? - futuro, na educação de crianças e adultos; também num importante fator de memória das sociedades.

No horizonte que se desponta, se faz urgente refletir sobre os desafios e as perspectivas que envolvem a produção do patrimônio cultural brasileiro, nesta primeira década do século XXI, com o objetivo de contribuir para uma reflexão que apreenda os sentidos do patrimônio como um permanente processo de produção de referenciais identitários de grupos, indivíduos, classes, etnias etc., e não mais somente de legitimação de um Estado e memória nacionais.

É no esboço deste novo retrato do Brasil que começa a ser desenhado que gostaria de situar a construção de uma nova representação da nação. Não é somente a seleção dos novos patrimônios culturais que interessa (ainda que a inflação patrimonial mereça nossa atenção), mas os dilemas que a prática preservacionista precisa enfrentar e o papel que caberia à educação patrimonial no projeto de reeducação das relações étnico-racais.

\section{Diversidade, educação e patrimônio cultural}

Tema caro este da diversidade cultural para a história do pensamento social brasileiro. Intelectuais e pesquisadores de diferentes matizes teóricas e ideológicas se dedicaram à temática, desde o mo- 
Diversidade e sentidos do patrimônio cultural: uma proposta...

mento em que decidiram compreender e definir o Brasil. Historiadores, sociólogos, modernistas e antropólogos se investiram, desde o final do século XIX, da missão de revelar a realidade da cultura brasileira guiados pela pergunta que a todos inquietava: "quem somos nós"?

A formulação de tal questão opera sempre em relação ao outro ou aos outros. Quando recorremos ao dicionário para buscar uma definição do termo diversidade, de imediato, se sobressaem diferença e dessemelhança. Então, quando buscamos definir a $\mathrm{Na}$ ção brasileira, definimos o Brasil em relação ao "outro", seja no sentido externo, seja no sentido interno (GUIMARÃES, 1988). É um movimento que diz respeito à relação entre o eu e o outro, entre eles e nós ou entre o diferente e a nossa comunidade e a nossa história. Assim, quando falamos de diversidade cultural, estamos falando de um auto-reconhecimento que diz respeito às diferenças e às semelhanças (GOMES, 2003, p.72).

Diferentes narrativas identitárias foram sendo construídas, sobretudo a partir das décadas de 20 e 30 do século XX, com o objetivo de interpretar o Brasil e entender o "ser brasileiro". Literatura, artes plásticas e historiografia, cada uma em sua especificidade, expressou a busca de nossas raízes em consonância com outras dimensões do social. Tão logo a experiência nacional passou a ser vista como resultado do entrecruzamento das matrizes européias, ameríndias e africanas, evidenciou-se a riqueza da diversidade étnico-cultural como signo de nossa alteridade. Dentro desse quadro de múltiplas referências, a memória do passado colonial trilhou o caminho consubstanciada pelo mito da democracia racial de Gilberto Freyre. Hipótese essa adotada com muito entusiasmo até fazerem-lhe frente os estudos sobre os negros e as relações raciais no Brasil, realizados pela chamada escola de sociologia paulista, após a década de 1940. Segundo Otavio Ianni, a ressonância da idéia de que o Brasil era uma democracia racial chegou até a UNESCO - preocupada com um mundo estilhaçado 
pela guerra e pela violência do racismo que alimentou os regimes nazi-facistas alastrando-se pelo resto do mundo - e partiu dela o interesse de esclarecer e estudar a situação racial no Brasil, incentivando e apoiando os estudos pioneiros de Roger Bastide e Florestan Fernandes na Universidade de São Paulo.

Com os trabalhos de Roger Bastide e Florestan Fernandes, em Negros e brancos em São Paulo, é que foi revelada a realidade do preconceito racial de par em par com o preconceito de classe e, portanto, o preconceito racial constitutivo da sociabilidade na sociedade brasileira. (IANNI, 2004, p. 10).

A partir desse contexto, organizações e movimentos criados, desde as décadas de 1920 e 1930, como a Frente Negra Brasileira, o Teatro Negro de Abdias do Nascimento, o II Congresso AfroBrasileiro, realizado em Salvador, entre outros, impulsionaram o surgimento de novos grupos de movimento negro que, apesar das diferenças, passaram a unificar a luta de resistência contra o preconceito e o racismo.

Nas análises que, até aquele momento, buscavam entender o processo de nossa formação histórico-cultural, era nítida a concepção hegemônica e hierárquica que orientou a contribuição de cada um dos segmentos sociais na configuração do povo brasileiro. Reconhecíamos a diversidade, mas outorgaríamos papéis diferenciados a brancos, negros e índios na construção da história e da cultura brasileira. Grosso modo, ocultaríamos mesmo um racismo camuflado nos discursos formadores do Brasil.

As instituições educacionais e a política de preservação do patrimônio histórico e artístico nacional tiveram papéis estratégicos na cristalização da memória nacional. Tal processo deixou marcas profundas na constituição de uma identidade nacional legitimadora de um passado homogêneo e postuladora de uma herança histórica e estética da chamada cultura superior e civilizada, notadamente de matriz luso-brasileira.

Anos 90, Porto Alegre, v. 15, n. 27, p. 233-255, jul. 2008 
Diversidade e sentidos do patrimônio cultural: uma proposta...

Silêncio, esquecimento e omissão são explícitos quanto à condição de sujeitos históricos de índios e negros, principalmente quando uma análise mais detida foca currículos escolares, festas cívicas e livros didáticos:

\begin{abstract}
Os livros didáticos, sobretudo os de história, ainda estão permeados por uma concepção positivista da historiografia brasileira, que primou pelo relato dos grandes fatos e feitos dos chamados "heróis nacionais", geralmente brancos, escamoteando assim a participação de outros segmentos sociais no processo histórico do país. Na maioria deles, despreza-se a participação das minorias étnicas, especialmente de índios e negros. Quando aparecem nos didáticos, seja através de textos ou de ilustrações, índios e negros são tratados de forma pejorativa, preconceituosa ou estereotipada. (FERNANDES, 2005, p. 380).
\end{abstract}

Para Circe Bittencourt, em Identidades e ensino da bistória no Brasil, a reflexão sobre identidade nacional e ensino de história deve levar em consideração as transformações da concepção e o uso político em que foi forjada a identidade nacional nos diferentes períodos da história brasileira. Associada à atuação do povo brasileiro na constituição da nação e, conseqüentemente, dos conteúdos históricos escolares, objetivava a formação de um sentimento nacionalista e de uma concepção de povo.

Dois aspectos precisam ser destacados ao analisarmos tais objetivos, observa a autora:

[...] seja nos textos oficiais ou nos textos produzidos por intelectuais de outras instituições, não se trata de uma concepção semelhante e pertencente a um projeto sempre homogêneo sobre a nação e sobre a educação. Deve-se, nessa perspectiva, conceber identidade nacional em seu sentido plural, por vezes, antagônicos, e nos diversos momentos em que se destaca como projeto nacional. (BIT'TENCOURT, 2007, p. 34).

Anos 90, Porto Alegre, v. 15, n. 27, p. 233-255, jul. 2008 
Também devemos considerar que "essa finalidade não é exclusividade da história, mas ela sempre esteve associada a outros objetivos educacionais mais amplos, assim como a outras disciplinas escolares." (BITTENCOURT, 2007)

Se, de um lado, o sistema educacional, com suas festas, livros didáticos, currículos, temáticas e conteúdos programáticos sobre o ensino de história revelou-se eficiente mecanismo ideológico na construção da identidade nacional - responsável por uma visão monoculturalista e eurocêntrica de nosso passado -, corroborou para esta política a institucionalização do patrimônio histórico e cultural pelo poder público.

Devemos considerar a gênese da noção de patrimônio histórico e artístico nacional atrelada à idéia de nação e formação do Estado Nacional. No caso francês, o Estado assumiu, no século XIX, a proteção legal dos bens culturais como documentos da nação em nome do "interesse público" e da "função pedagógica" para formação do cidadão. Ciente de sua capacidade simbólica de representar a nação, fundamentou toda uma política estatal de preservação e salvaguarda do patrimônio, paradigma para muitos países da Europa, África e América Latina.

O sentimento de pertencimento que enuncia a idéia de nação, a "comunidade imaginada", na acepção de Benedict Anderson (1989), ganharia materialidade sob a mediação do patrimônio histórico e dos valores a ele atribuídos, localizando-a, agora, no espaço e no tempo. Nesta operação, não fica difícil entender a invenção de patrimônios nacionais como um processo constitutivo de reinvenção do passado historicamente determinado. Seu sentido está em reunir referenciais comuns a todos habitantes de um mesmo território, unificando-os em torno de pretensos interesses e tradições comuns, impondo ainda uma língua nacional e uma história oficial que se apropriou de memórias individuais e de grupos (RODRIGUES, 2007, p. 17). 
Diversidade e sentidos do patrimônio cultural: uma proposta...

Tributário do modelo estatal francês, o Brasil, como muitos outros países da América Latina, desenvolveu uma política de preservação do patrimônio conduzido pelo ideário nacionalista dos anos de 1930. A consciência do sentido de construção de uma arte e uma cultura nacionais levou os modernistas ao resgate do passado colonial como signo do Brasil moderno. Da ruptura com os valores artísticos e estéticos eurocêntricos, o movimento modernista encontrou no barroco mineiro do século XVIII os referenciais de nossa identidade nacional ou da brasilidade como preferiam.

É Mário de Andrade quem semeia uma concepção de patrimônio ampla e plural que procurava abarcar todas as manifestações do povo brasileiro. No texto do projeto para a criação do Serviço do Patrimônio Artístico Nacional, em 1936, sobressai na definição de arte patrimonial do escritor a consciência da diversidade cultural brasileira e do reconhecimento de que essa se exprime tanto em formas materiais quanto imateriais, tangíveis ou intangíveis. Derrotado, somente partes do projeto são incorporadas na criação do Serviço do Patrimônio Histórico e Artístico Nacional (SPHAN), no contexto do Estado Novo (1937-1945).

Por muitos anos, vigorou no imaginário brasileiro uma idéia de patrimônio cristalizada como sinônimo de edificações e arte erudita. Segundo o Decreto-Lei n. 25-37, em funcionamento até hoje, entende-se por Patrimônio Histórico e Artístico Nacional “o conjunto de bens móveis e imóveis existentes no país e cuja conservação seja de interesse público, quer por sua vinculação a fatos memoráveis da História do Brasil, quer por seu excepcional valor arqueológico ou etnográfico, bibliográfico ou artístico" (1937).

Os conceitos de monumentalidade e de excepcionalidade que orientaram a política de preservação de nosso patrimônio, em conjunto com o tombamento, contribuíram para uma mentalidade preservacionista que se difundiu entre os Estados e Municípios do País. Na trajetória do SPHAN, criado pelo decreto supracitado, até a década de 1970, consolidou-se uma prática preservacionista 
que privilegiou bens e monumentos arquitetônicos, em conformidade com os valores estéticos e históricos representativos de determinados estilos arquitetônicos ("barroco colonial" e, posteriormente, o modernista) e/ou dos fatos memoráveis da história, segundo o conceito clássico de patrimônio. Assim foram tombados igrejas barrocas, fortes militares, engenhos, casas-grandes, casas de câmara e cadeia, chafarizes e pontes. $\mathrm{Na}$ "fase heróica" do SPHAN, caracterizada pela chamada "sacralização da memória em pedra e cal" (Nogueira, 1995), predominaram igualmente os conceitos clássicos de história e de cultura, respectivamente a oficial e a erudita.

A redução do Brasil a esse repertório de bens de "excepcional valor", traduzida pela exclusividade do tombamento, revela o caráter político da seleção de nosso legado cultural. Ao privilegiar as expressões culturais de uma determinada classe ou grupo social como a de tradição européia - herança luso-colonial geralmente identificada com o poder constituído -, a noção de patrimônio e a política oficial de preservação revelaram-se elitistas e conservadoras, principalmente num país caracterizado pela contradição e pluralidade étnico-cultural como o nosso.

Uma gama enorme de bens significativos não foi preservada por não se encaixar nessa categorização engessada de patrimônio. Ficaram de fora ou foram destruídos ou relegados ao esquecimento como as senzalas, os quilombos e os terreiros, as primeiras fábricas, os cortiços e as vilas operárias.

Derrotada pela hegemonia da "pedra e cal", a semente do projeto andradiano para o patrimônio encontra ressonância na gestão de Aloisio Magalhães, nos idos dos anos de 1970, quando é incorporada aos trabalhos do CNRC - Centro Nacional de Referência Cultural e da FNPM - Fundação Nacional Pró-Memória.

A partir desta década, a ressemantização do conceito aponta para o chamado patrimônio cultural em sua versão atual. Notamos que não se trata apenas de uma simples questão semântica, mas da abrangência que seu sentido passou a ter segundo uma concepção 
Diversidade e sentidos do patrimônio cultural: uma proposta...

antropológica de cultura em vigor (FONSECA, 1997). Em oposição a um sentido de patrimônio indissociável da idéia de culto e de sagrado atribuído aos bens e monumentos carregados de excepcionalidade, encontra-se a valorização do patrimônio cultural entendido como um fator de memória das sociedades (RODRIGUES, 2001, p. 17).

É uma noção de patrimônio que busca abarcar a produção dos esquecidos reforçando seu valor cultural. Situado num movimento maior de revisão da historiografia - e que, no Brasil, coincide com o surgimento dos movimentos sociais no processo de redemocratização -, o conceito de patrimônio cultural colocou no centro do debate outros atores que não os burocratas e intelectuais. Neste sentido, o patrimônio passou a ser visto não apenas como remanescente de uma memória histórica - informadora de uma identidade nacional que pouco diz à maioria da população -, mas como importante testemunho das temporalidades que compõem as múltiplas experiências vividas, individual ou coletivamente; portanto, campo privilegiado na reelaboração das novas identidades coletivas e instrumento fundamental para o reconhecimento dos grupos sociais que as constroem.

A efervescência dos movimentos sociais, sobretudo os ligados à etnia e ao gênero, colaborou para a emergência de uma nova relação entre Estado e Sociedade, incidindo diretamente sobre as políticas públicas, respaldadas, no futuro próximo, pela constituição de 1988. Dos movimentos indigenistas, estão a pressão pela demarcação das terras e o reconhecimento de sua cultura; do movimento de consciência negra, está a radicalização da luta contra qualquer forma de preconceito e discriminação racial, exigindo, com base no direito à diferença, o estudo e a valorização dos aspectos da cultura afro-brasileira. No conjunto das reivindicações que exigiam uma maior participação e o efetivo direito à cidadania, encontramos o que Marilena Chauí denominou de "cidadania cultural", na qual o "direito à memória" tornou-se um substrato relevante no escopo das políticas inclusivas. 
A repercussão desse movimento político no contexto da prática preservacionista pelo IPHAN começa a ganhar força quando do tombamento do Terreiro da Casa Branca, em Salvador, em 1984, e da Serra da Barriga, em Alagoas (República dos Palmares), em 1986. Marcos simbólicos de uma nova concepção de patrimônio cultural que vinha se delineando traduzem a apropriação do tombamento por parte da população civil na política de preservação. Nos dois casos, todo processo de tombamento foi encaminhado por representantes de instituições culturais e acadêmicas, por representantes dos movimentos negros e por grupos locais.

Considerado o primeiro terreiro de candomblé instalado no Brasil, veio a ser reconhecido como elemento crucial na preservação da identidade religiosa de determinados segmentos sociais no Brasil, especialmente negros. Identificado à tradição nagô, o terreiro Casa Branca é considerado por muitos como exemplo de "pureza" desta tradição. Antropólogos foram chamados a dar pareceres sobre a importância histórica e sociocultural do Casa Branca e recomendaram enfaticamente o seu tombamento em virtude de estar associado à memória cultural dos negros e dos brasileiros em geral (GONÇALVES, 1996, p. 80).

Simbólico e emblemático, o tombamento do Terreiro Casa Branca representou, antes de tudo, uma vitória política dos grupos envolvidos, tendo em vista a iminente ameaça real de despejo do local. De alguma forma, sugere o começo de uma política de reparos à violência histórica que marcou a comunidade religiosa afrobrasileira, nesse e noutros espaços similares por todo o Brasil, desde o início da Primeira República.

Sob essa perspectiva, a relevância do tombamento de um bem cultural, sobretudo para grupos econômicos e socialmente desfavorecidos, pode significar benefícios de ordem material e simbólica, além de demonstração de poder político (FONSECA, 1997, p. 206). A comunidade religiosa do terreiro reconhecia a importância daquele 
espaço como um lugar de prática simbólica coletiva que dizia respeito às redes sociais daquele grupo que atuava no mundo do candomblé. Diante da identidade cultural ameaçada - já que o espaço possibilita o auto-reconhecimento -, justificava-se a ação de apropriação e a luta pela preservação do terreiro como "lugar de memória".

Grande parte da polêmica que se instaurou no processo de elevação do Terreiro Casa Branca a monumento nacional centrou foco na incongruência do tombamento. Como era possível tombar um bem arquitetônico cujo espaço abrigava algo vivo e dinâmico como um culto religioso popular com seus diversos rituais, quando o tombamento pressupõe sempre permanência e imutabilidade? Esta é uma visão distorcida do sentido de patrimônio categorizado equivocadamente pela dicotomia entre material e imaterial, como já comentamos anteriormente.

\section{Novos patrimônios, novas identidades, múltiplas memórias: PCNS, decreto 3.551/2000 e o patrimônio cultural afro-brasileiro}

A construção do patrimônio cultural da nação, percebida como prática social, evidencia um campo de conflito material e simbólico no processo de constituição da memória coletiva ou de grupos. Portadora de um regime de historicidade, a escolha de determinados bens culturais como representativos da identidade nacional ou de determinados grupos ou etnias é sempre uma operação política que se traduz igualmente na escolha por um passado histórico e cultural revelador da luta permanente pela representação da nação.

Considerando a pluralidade cultural como vetor das diretrizes que norteiam o processo de reelaboração da nova perspectiva de ensino para pensar a questão da brasilidade e da identidade nacional, se faz necessário articular tal processo ao da ressemantização do conceito de patrimônio cultural e das políticas de preservação a ele relacionadas no final do século XX. 
Se durante mais de sessenta anos vigorou no Brasil uma concepção de patrimônio assentada no valor de excepcionalidade, na qual o estatuto jurídico do tombamento privilegiou os bens culturais de caráter erudito e de monumentalidade - a memória em pedra e cal - uma noção mais ampla e plural de patrimônio cultural só foi possível a partir do decreto 3.551, de 4 de agosto de 2000, que instituiu o registro e o inventário dos bens culturais de natureza imaterial ou intangível. A desmaterialização do patrimônio possibilitou a ampliação do acervo da brasilidade - expressão de línguas, festas, rituais, danças, mitos, músicas, comidas, lugares, saberes e fazeres - e imprimiu uma visão menos redutora de Brasil.

A eleição dos novos bens, ou melhor, de novas formas de se conceber a condição de patrimônio cultural nacional, também permite que diferentes grupos sociais, utilizando as leis do Estado e o apoio de especialistas, revejam as imagens e alegorias do passado, do que querem guardar e definir como próprio e identitário. $\mathrm{O}$ decreto abre a possibilidade para o surgimento de novos canais de expressão cultural e luta política para grupos da sociedade civil antes silenciados, que são detentores de práticas culturais imateriais locais e tidas como tradicionais. (ABREU, 2007, p. 356).

Novos patrimônios, novas identidades, múltiplas memórias. A emergência de um novo campo para o patrimônio cultural se configura. Postulado pela concepção antropológica de cultura que o orienta, sinaliza para a necessidade de colocar em debate a reorientação das políticas públicas de preservação a partir do novo sentido do patrimônio. Na lógica dessa nova correlação de forças que se estrutura, está uma "vontade de memória", para usar a expressão dos estudiosos que vêm se dedicando a compreender o fenômeno da "dilatação da memória histórica", como Jacques Le Goff (1992), ou a criação dos chamados "lugares de memória", obsessão da sociedade contemporânea, segundo Pierre Nora (1993). 
Diversidade e sentidos do patrimônio cultural: uma proposta...

Síntese da bandeira democrática que conduziu os movimentos populares, nos anos 80, na luta pela ampliação da noção de patrimônio, cultura e inventário, os artigos 215 e 216 da Constituição de 1988, assim os definem:

Artigo 215. O Estado garantirá a todos o pleno exercício dos direitos culturais e acesso às fontes da cultura nacional, apoiará e incentivará a valorização e difusão das manifestações culturais.

\1. O Estado protegerá as manifestações das culturas populares, indígenas e afro-brasileiras e das de outros grupos participantes do processo civilizatório nacional.

$\int 2$. A lei disporá sobre a fixação de datas comemorativas de alta significação para os diferentes segmentos étnicos nacionais.

Artigo 216. Constituem patrimônio cultural brasileiro os bens de natureza material e imaterial, tomados individualmente ou em conjunto, portadores de referência à identidade, à ação, à memória dos diferentes grupos formadores da sociedade brasileira, nos quais se incluem:

I - as formas de expressão;

II - os modos de criar, fazer e viver;

III - as criações científicas, artísticas e tecnológicas;

IV - as obras, objetos, documentos, edificações e demais espaços destinados às manifestações artístico-culturais;

$\mathrm{V}$ - os conjuntos urbanos e sítios de valor histórico, paisagístico, artístico arqueológico, paleontológico, ecológico e científico.

\1. O Poder Público, com a colaboração da comunidade, promoverá e protegerá o patrimônio cultural brasileiro por meio de inventários, registros, vigilância, tombamento e desapropriação, e de outras formas de acautelamento e preservação.

Anos 90, Porto Alegre, v. 15, n. 27, p. 233-255, jul. 2008 
\2. Cabem à administração pública, na forma da lei, a gestão da documentação governamental e as providências para franquear sua consulta a quantos dela necessitem.

$\int 3$. A lei estabelecerá incentivos para a produção e o conhecimento de bens e valores culturais.

\4. Os danos e ameaças ao patrimônio cultural serão punidos pela lei.

$\int 5$. Ficam tombados todos os documentos e os sítios detentores de reminiscências históricas dos antigos quilombos.

Validados por esta Constituição, os PCNs e o decreto $3.551 \backslash 2000$ sugerem aproximações entre a política educacional do Ministério da Educação e Cultura (MEC) e a política de patrimônio cultural instituída pelo IPHAN. Há uma explícita interface entre os dois documentos, sobretudo no que tange à formação do povo brasileiro pelas diferentes etnias e à constituição de uma identidade nacional, respaldada pela pluralidade e diversidade cultural, ou seja, a brasilidade. Nos planos dos Parâmetros Curriculares Nacionais para uma educação multicultural, colocou-se no âmbito dos temas transversais a necessidade dos estudos da pluralidade cultural, cujos objetivos, dentre outros, está o conhecimento e a valorização da pluralidade do patrimônio sócio-cultural do país, identidades e memórias da nação.

O decreto $3.551 \backslash 2000$ coloca como prioridade para o registro de determinados bens culturais de natureza imaterial ou intangível a sua continuidade histórica e relevância nacional para a memória, identidade e formação da sociedade brasileira. No Programa Nacional do Patrimônio Imaterial, criado pelo decreto, está o reconhecimento e a valorização do patrimônio a partir da instituição do inventário e do registro. A meta é contribuir para preservação da diversidade étnica e cultural do país e para a disseminação de informações sobre o patrimônio cultural brasileiro a todos os segmentos da sociedade. 
O registro corresponde à identificação e à produção de conhecimento sobre o bem cultural de natureza imaterial e equivale a documentar, pelos meios técnicos mais adequados, o passado e o presente dessas manifestações, em suas diferentes versões, tornando tais informações amplamente acessíveis ao público. O objetivo é manter o registro da memória desses bens culturais e de sua trajetória no tempo, porque assim se pode “preservá-los". (SANT'ANNA, 2000, p. 52).

Os bens culturais selecionados para o registro têm sua inscrição garantida nos seguintes livros específicos: Livro de registro dos saberes (conhecimento e modos de fazer enraizados no cotidiano das comunidades); Livro das celebrações (festas, rituais que marcam a vivência coletiva do trabalho, da religiosidade, do entretenimento e de outras práticas da vida cotidiana); Livro das formas de expressão (manifestações literárias, musicais, plásticas, cênicas e lúdicas); Livro dos Lugares (feiras, mercados, santuários, praças e demais espaços onde se concentram e se reproduzem práticas culturais coletivas).

Em pouco tempo, já era nítida a repercussão dessa nova reorientação das políticas públicas no reconhecimento da diversidade étnico-cultural do país. No âmbito da educação está a oficialização, no calendário escolar, do "Dia Nacional da Consciência Negra", em 20 de novembro - alusão à morte de Zumbi dos Palmares, marco de resistência do negro à escravidão - há muito tempo consagrado pelo movimento negro.

A grande mobilização das comunidades quilombolas é outro exemplo da luta pelo reconhecimento da cultura afro-brasileira, uma vez que o registro e a propriedade das terras estão condicionados aos referenciais identitários dos afro-descendentes. Existem, no território brasileiro, mais mil comunidades nesse movimento. No Ceará, 84 comunidades quilombolas esperam pela regularização de suas terras: Lagoa dos Ramos, Goiabeiras e Alto Alegre, em Horizonte; Base Retiro e Caetanas, em Pacajus; Queimadas, em Crateús e outras. Alguns indícios apontam a existência de cinco comunidades 
quilombolas até mesmo na cidade de Fortaleza: Jardim Iracema, Barra do Ceará, Bom Jardim e duas no Pirambu (O POVO, 2006, p. 7).

A arte kusiwa, pintura corporal e arte gráfica dos índios wajãpi do Amapá, inaugurou, em 2002, o registro no Livro dos Saberes como patrimônio cultural brasileiro. Logo, em 2003, ganharia o título de "obra-prima do patrimônio oral e imaterial da humanidade" concedido pela UNESCO. No caso do patrimônio cultural afro-brasileiro, o Samba de roda do recôncavo baiano estréia o Livro Formas de Expressão, em 2004; no ano seguinte, recebe da UNESCO aquele mesmo título.

Para Carlos Sandroni, autor do dossiê que encaminhou o Samba de Roda à UNESCO, a força do samba é percebida como catalisadora de emoções, de identidades e de pertencimentos. Samba "corrido" e samba "chula" são as duas variantes principais dentre as inúmeras modalidades de samba de roda do recôncavo.

De caráter essencialmente lúdico, não tem data nem local
exclusivo para ocorrer, podendo no entanto associar-se ao
calendário religioso, como um encerramento intermezzo pro-
fano nas festas de santos católicos ou divindades afro-brasi-
leiras ou caboclas. Em particular, são célebres os sambas as-
sociados às festas dos santos Cosme e Damião, no final do
mês de setembro. O samba de roda pode acontecer dentro
de casa ou ao ar livre, num bar, numa praça ou num terrei-
ro de candomblé. Basta que haja espaço para alguns músi-
cos, para a roda de assistentes/participantes e para a dança
no meio da roda. (2005, p. 47).

Outras formas de samba igualmente catalisadoras de referências culturais da matriz afro-brasileira - embora não necessariamente de identidade étnica - também receberam o título de patrimônio cultural imaterial brasileiro a partir de seus registros no Livro Formas de Expressão: Tambor de Crioula (2005), Jongo do Sudeste (2005) e Samba do Rio de Janeiro: samba de terreiro, partido alto e samba enredo (2007).

Anos 90, Porto Alegre, v. 15, n. 27, p. 233-255, jul. 2008 
Diversidade e sentidos do patrimônio cultural: uma proposta...

Entretanto, questões como a quem pertence o samba? Quem pode falar em nome dele? "Samba" ou "sambas brasileiros"? E tantas outras que suscitou o antropólogo Carlos Sandroni, têm alimentado as acaloradas discussões entre intelectuais e representantes das manifestações quando da fundamentação dos dossiês para futuros patrimônios culturais brasileiros."Memória em disputa": evidências concretas de conflitos e tensões marcam o campo da cultura e do patrimônio, já dissemos.

É o caso também do registro do Ofício de Baianas de acarajé no Livro dos Saberes. Elemento significativo do sistema culinário baiano - associado aos referenciais identitários étnico-culturais -, o acarajé representa tanto o universo simbólico dos terreiros de candomblé quanto uma prática cotidiana da economia informal que tem nas chamadas comidas de rua um amplo e diversificado ramo de atividade. As baianas de acarajé são responsáveis pela mediação entre os terreiros e os espaços da cidade. Seus trajes e tabuleiros contribuem para a construção da paisagem da cidade de Salvador, cartão postal da "baianidade".

Herdeiras dos segredos da culinária votiva, de tradição iorubá, no candomblé, elas são as iabassês, detentoras do conhecimento de preparação das "comidas de santos". Comida sagrada e ritualística, o acarajé é um importante legado dos cultos africanos cuja ancestralidade remete às oferendas aos orixás, sobretudo Xangô e sua mulher Oiá (Iansã). Embora a venda do acarajé na rua tenha, na origem, vinculação com a "obrigação" - autorização que as mulheres iniciadas nos rituais tradicionais do candomblé solicitavam para arrecadar fundos para "fazer o santo" -, atualmente a produção e venda de acarajé na rua não se restringe mais à tradição do candomblé. Pode-se inclusive encontrar homens e evangélicos na atividade, o que tem gerado críticas depreciativas sobre o inventário e sua elevação a patrimônio cultural.

Imerso na complexidade e dinâmica cultural das grandes metrópoles brasileiras, sobretudo Salvador, o acarajé está sujeito 
a variados processos de apropriações e ressignificações nos diferentes segmentos da sociedade - sem, contudo, perder seu vínculo com um universo cultural específico e fundamental na formação da identidade brasileira. (MENDONÇA et al., 2005, p. 56).

O conhecimento realizado pelo inventário e o reconhecimento com a inscrição em algum dos Livros de Registro conferindo o título de patrimônio cultural do Brasil, trouxeram significativos ganhos para o patrimônio étnico-cultural, notoriamente o afro-brasileiro. A inserção de novos bens, de natureza imaterial, tem contribuindo de forma decisiva para o fortalecimento de uma reeducação étnico-racial na luta contra qualquer forma de preconceito e discriminação e no fortalecimento da auto-estima dos afro-descendentes.

A centralidade do inventário na reorientação e no fomento das políticas públicas do patrimônio tem rompido com aquela idéia igualmente cristalizada no imaginário de que preservação era sinônimo de tombamento. Amplamente apropriado por instituições culturais, associações comunitárias, universidades, escolas etc., o inventário vem potencializando o exercício da educação patrimonial e contribuindo para a valorização das memórias e histórias locais.

\section{Educação patrimonial: considerações finais}

Feito o trajeto, fica, então, uma idéia de patrimônio histórico-cultural cada vez mais vinculado aos valores que indivíduos e/ ou grupos atribuem a determinados bens como signos da cultura, referenciais das identidades e memórias sociais. A consciência do novo sentido do patrimônio como um lugar de memória - não mais restrito a uma ideologia nacionalista de legitimação dos Estadosnações - revelou um campo simbólico de conflitos e disputas, dimensionando a prática preservacionista para além da inclusão dos novos patrimônios. A potencialidade desta nova perspectiva está na 
possibilidade de os diferentes segmentos sociais se apropriarem de sua herança cultural e reivindicar a valorização e o reconhecimento de qualquer tipo de patrimônio como um direito à memória e ao pleno exercício da cidadania.

A educação patrimonial tem papel fundamental na construção desta nova sensibilidade. Tomando o Patrimônio Cultural como fonte e matéria-prima para o conhecimento e a aprendizagem de crianças e adultos, e também dos grupos sociais, as ações educativas devem proporcionar um contato direto com o patrimônio em sua dimensão tangível ou intangível. A experiência com esses documentos possibilita a todos os envolvidos nesta experiência o conhecimento, a valorização e a apropriação de um importante legado cultural.

"Conhecer para preservar", "preservar para valorizar" e se "auto-reconhecer": esta deve ser a meta da educação patrimonial na construção de um conhecimento crítico assentado na diversidade. Não somente no sentido de criar uma consciência preservacionista sustentável, mas sobretudo em garantir às comunidades o direito de intervir diretamente na seleção do seu patrimônio como importante elemento de fortalecimento das identidades e memórias locais.

A Educação Patrimonial é um instrumento de "alfabetização cultural" que possibilita ao indivíduo fazer a leitura do mundo que o rodeia, levando-o à compreensão do universo sociocultural e da trajetória histórico-temporal em que está inserido. Esse processo leva ao reforço da auto-estima dos indivíduos e comunidade e à valorização da cultura brasileira, compreendida como múltipla e plural. (HORTA, et al., 1999, p. 6).

Diversity and meanings of the cultural patrimony: a proposal to read the trajectory of recognition of Afro-Brazilian culture as national patrimony Abstract. Considering that the recognition and appreciation of cultural diversity imply a re-education of the ethnic-racial relations beyond school walls, the text aims at articulating the guidelines which rule the process of rebuilding of the new 
perspective of teaching to promote a reflection on the "Brazilianess" issue towards the re-semantization of the concept of cultural patrimony. Based on the decrees and laws of the official policies of cultural patrimony preservation in Brazil at the end of the 20th century, this text reflects the trajectory of construction of the patrimony as a long process which is the struggle for the appreciation, and recognition of the Afro-Brazilian culture.

Keywords: Cultural Patrimony. Diversity. Patrimonial Education. Identity. Memory.

\section{Documentos}

BRASIL. Constituição (1988). Constituição da República Federativa do Brasil. Brasília: DF \Senado, 1988.

Diretrizes Curriculares Nacionais para a Educação das Relações Étnico-Raciais e para o Ensino de História e Cultura AfroBrasileira e Africana. Brasília: MEC/SEPPIR, 2004.

Decreto-lei 25 de 1937.

Decreto 3.551 de 4 agosto de 2000.

Dossiê final das atividades da Comissão e do Grupo de Trabalho Imaterial.

\section{Referências}

ABREU, Marta. Cultura imaterial e patrimônio histórico nacional. In: Cultura Política e leituras do passado: historiografia e ensino de história. Rio de Janeiro: Civilização Brasileira, 2007.

ANDERSON, Benedict. Nação e Consciência Nacional. São Paulo: Ática, 1989.

BITTENCOURT, Circe M. F. Identidades e ensino da história no Brasil. In: Ensino da história e memória coletiva. Porto Alegre: Artmed, 2007.

CANCLINI, Nestor. O patrimônio cultural e a construção do imaginário nacional. In: Revista do Instituto do Patrimônio Histórico e Artístico Nacional. Brasília: IPHAN/ MINC, n. 23, 1994.

Anos 90, Porto Alegre, v. 15, n. 27, p. 233-255, jul. 2008 
Diversidade e sentidos do patrimônio cultural: uma proposta...

CHOAY, Françoise. A alegoria do patrimônio. São Paulo: UNESP, 2001.

DEPARTAMENTO DE PATRIMÔNIO IMATERIAL/IPHAN. Os Sambas, as rodas, os bumbas, os meus e os bois: A trajetória da salvaguarda do patrimônio cultural imaterial no Brasil. Brasília: IPHAN, 2006.

FERNANDES, Ricardo O. Ensino de histórica e diversidade cultural: desafios e possibilidades. In: Caderno Cedes. Campinas: UNICAMP, vol. 25, n. 67, 2005.

FONSECA, Maria Cecília L. O patrimônio em processo: Trajetória da política federal de preservação no Brasil. Rio de Janeiro: UFRJ \IPHAN, 1997.

- Para além da pedra e cal: por uma concepção ampla de patrimônio cultural. In: Memória e Patrimônio: Ensaios Contemporâneos. Rio de Janeiro: DP\&A, 2003.

GOFF, Jacques Le. História e Memória. Campinas: UNICAMP, 1992.

GOMES, Nilma Lino. Educação e diversidade étnico-cultural. In: Diversidade na educação: reflexões e experiências. Brasília: Secretaria de Educação Média e Tecnológica, 2003.

GONÇALVES, Reginaldo. A retórica da perda: os discursos do patrimônio cultural no Brasil. Rio de Janeiro: UFRJ \IPHAN, 1996.

GUIMARÃES, Manoel Luís Salgado. Nação e Civilização nos Trópicos: O IHGB e o Projeto de uma História Nacional. In: Estudos Históricos. Rio de Janeiro: FGV/ CPDOC, 1988.

HORTA, GRUMBERG e MONTEIRO (org.). Guia básico de educação patrimonial. Brasília: IPHAN \Museu Imperial, 1999.

IANNI, Otavio. Otavio Ianni: o preconceito racial no Brasil (Entrevista). In: Estudos Avançados: O negro no Brasil. São Paulo: USP, 2004, n. 50.

MENDONÇA, VIANA, NOGUEIRA, LODY. O Ofício de Baianas de acarajépatrimônio cultural. In: Registro e políticas de salvaguarda para as culturas populares. Rio de Janeiro: IPHAN/CNFCP, 2005. (Encontros e Estudos)

NOGUEIRA, Antonio Gilberto R. Por um inventário dos sentidos: Mário de Andrade e a concepção de patrimônio e inventário. (Prêmio Silvio Romero 2004) São Paulo: HUCITEC $\backslash$ FAPESP, 2005.

- O Serviço do Patrimônio Histórico e Artístico Nacional e a Redescoberta do Brasil: A sacralizaçao da memória em pedra e cal. São Paulo: PUC-SP, 1995. (Dissertação de Mestrado)

NORA, Pierre. Entre Memória e História: A problemática dos lugares. In: Projeto História: História \& Cultura. São Paulo: PUC, n. 10,1993.

Anos 90, Porto Alegre, v. 15, n. 27, p. 233-255, jul. 2008 


\section{Antonio Gilberto Ramos Nogueira}

RODRIGUES, Marly. Preservar e consumir: o patrimônio histórico e o turismo. In: Turismo e Patrimônio Cultural. São Paulo: Contexto, 2001.

SANDRONI, Carlos. Questões em torno do dossiê do samba de roda. In: Registro epolíticas de salvaguarda para as culturas populares. Rio de Janeiro: IPHAN/CNFCP, 2005. (Encontros e Estudos)

SANT'ANNA, Márcia. A face imaterial do patrimônio cultural: os novos instrumentos de reconhecimento e valorização. In: Memória e Patrimônio: Ensaios Contemporâneos. Rio de Janeiro: DP\&A, 2003.

SEGALA, Lygia. Identidade, educação e patrimônio: trabalho do Laboep. Revista Eletrônica IPHAN. Disponível em: http://www.revista.iphan.gov.br/materia. php?id $=138$

VIEIRA, Camila. A difícil vida de lá. In: O POVO: Vida \& Arte. Fortaleza: 20/11/2006, p. 7.

Recebido em 30/04/2008

Aprovado em 29/06/2008

Anos 90, Porto Alegre, v. 15, n. 27, p. 233-255, jul. 2008 
